\title{
Erratum to: Combined endonasal and sublabial endoscopic transmaxillary approach to the pterygopalatine fossa and orbital apex
}

\author{
Maysam Alimohamadi ${ }^{1,2,3}$ - Mohamadreza Hajiabadi ${ }^{1,2,3}$ • Venelin Gerganov ${ }^{2}$. \\ Rudolf Fahlbusch $^{2} \cdot$ Madjid Samii $^{1,2,3}$
}

Published online: 16 April 2016

(C) Springer-Verlag Wien 2016

Erratum to: Acta Neurochir (2015) 157:919-929

DOI 10.1007/s00701-015-2402-z

Affiliations of all authors are corrected in this article.

The online version of the original article can be found at doi: http://dx.doi. org/10.1007/s00701-015-2402-z.

\footnotetext{
Maysam Alimohamadi

alimohamadi59@gmail.com

1 Brain and Spinal Cord Injury Research Center (BASIR),

Neuroscience Institute, Tehran University of Medical Sciences

(TUMS), Tehran, Iran

2 International Neuroscience Institute, Rudolf Pichlmayr Street, No. 4, 30625 Hannover, Germany

3 Iranian International Neuroscience Institute, Tehran University of Medical Sciences, Tehran, Iran
} 